\title{
Prevention of Work-related Musculoskeletal Disorders in Grapes Pinching by Using Electro-motion Scissors Designed Ergonomically
}

\author{
Hyeseon Chae ${ }^{1}$, Sungcheol Kim ${ }^{1}$, Kwanwoo Kim ${ }^{2}$, Kyungsuk Lee ${ }^{1}$, Hoycher Kim ${ }^{1}$, Keunsang Park ${ }^{3}$ \\ ${ }^{1}$ National Academy of Agricultural Science, Rural Development Administration, Suwon, 441-707 \\ ${ }^{2}$ The Foundation of Agri. Tech. Commercialization and Transfer, Suwon, 441-857 \\ ${ }^{3}$ Department of Industrial Engineering, konkuk University, Seoul, 143-701
}

\begin{abstract}
Objective: The purpose of this study is to assess the reducing effect of workload on developed electro-motion scissors. Methods: To achieve this, we measured the pressure distribution, Joint angle of fingers and JSI(Job Strain Index) for electro-motion scissors and hand-operated scissor in objective assessment and surveyed the uncomfortable degree in subjective assessment. Results: As a result, The peak of pressure in the electro-motion scissors was generally lower than the hand-operated scissors. JSI and overall joint angle of fingers for the electro-motion scissors were remarkably lower than the hand-operated scissors. Also, the subjective uncomfortable degree showed that the uncomfortable point of electro-motion scissors were generally lower than the hand operated scissors. Conclusion: The impact of reducing the work load as well as distributing the pressure around the hand by using electro-motion scissors during grapes pinching was confirmed.
\end{abstract}

Keywords: Grapes pinching, MSDs; musculoskeletal disorders, Electro-motion scissors, Hand pressure, JSI, Hand/Wrist posture

\section{Introduction}

농업인의 경제활동 인구의 감소, 농업인의 고령화, 여성화 는 결과적으로 경지면적의 증가를 가져왔으며, 심각한 노동 력의 감소 및 노동강도의 증가를 가져왔다. 노동강도의 증가 와 더불어 노동인구의 고령화는 젊은이에 비해 생체 회복력 이 떨어지는 노인들의 근골격계 질환의 증가를 가져오며, 전 체 농업인의 근골격계질환 유병률을 높이는 것으로 사료된 다(RDA, 2009). 또한 많은 농가에서 적은 작업인원으로 다양한 유형의 농작업을 과도하게 수행하는 열악한 작업조 건으로 인해, 농작업 부담이 가중되고 이에 따라 농작업으로 인한 재해도 점차 증가하고 있다(RDA, 2004).

포도재배 같은 과수작업은 연중 서서 작업하며 순치기 작
업과 알솎기 작업은 장시간 반복적인 작업이 많아 목, 어깨, 손, 손목 등에 부담을 주어 근골격계 질환을 쉽게 발생시키 는 작업이다. 특히, 포도 순치기 작업은 상지의 수작업이 주 를 이루는 작업인데, 손의 반복적인 움직임으로 인한 손과 손목의 통증을 호소하는 비율이 $41.6 \%$ 로 높게 나타났다 (Jeong et al., 2009). 2006년도에 농촌진흥청에서 보고된 것을 보면, 포도재배 농업인의 근골격계 질환 유병율이 매우 높은 수준으로 보고되고 있어, 이에 대한 개선대책이 시급한 것으로 나타났는데, 이는 포도 순치기 작업의 단순반복 증가 와 불편한 작업자세에 기인하는 것으로 보인다.

수작업의 피해사례는 자동화되지 않는 시설 현장에서 많 이 발생되고 있다. 미국의 경우, 2001년 전체 산업에서 상해 및 질병 발생률이 100 명당 5.7 건인데 비해, 업무의 대부분 이 수작업인 제조업에는 8.1건으로 상대적으로 높은 실정이 
며, 전체 작업장 질병의 $65 \%$ 인 216,400 건이 반복적인 수 작업과 관련이 있다(Bureau of Labor Statistics, 2002). 수작업에서의 피해는 수공구의 구조와 밀접한 관계가 있는 데, 많은 작업장에서 사용하기 편하고 효율적으로 할 수 있 도록 설계된 수공구를 사용하여 작업을 진행하고 있음에도, 여전히 많은 작업자들은 수공구 사용으로 인해 근골격계질 환에 노출되고 있으며, 주로 근육, 건 그리고 신경 등과 관 련된 부위에서 통증을 호소하고 있다(Kong et al., 2009).

수작업에 관한 질환들의 가장 큰 원인은 반복성이라 할 수 있다. Kuorinka and Forcier(1995)는 상지의 반복적인 움 직임이 누적외상성 장해(cumulative trauma disorders)를 발생시키는 가장 중요한 위험 요인이라고 하였다. 과도한 반 복과 연관이 있는 누적외상성 장해는 수공구를 반복 사용하 는 산업이나 직무에서 그 발생율이 높으며, 공구의 부적절한 설계에 그 원인이 있다(Rosemary \& Conolly, 2003). 일반 적으로 알려져 있는 권장된 수공구 설계는 손 형태에 맞고 되도록 손목을 곧게 유지할 수 있어야 하며 잡을 때 손가락 전체를 이용하는 공구로써 설계하는 것이 바람직하다(Yang, 2004). Armstrong and Chaffin(1987)는 잦은 손목 움직 임과 부적절한 손목자세에서의 작업이 상지 작업관련성 근 골격계질환과 밀접한 관련이 있다고 하였다. 수공구에 대한 손의 압력에 관해서는, 수공구의 손잡이가 압력에 민감한 부 분에 닿아 신경과 혈관에 압박을 가하게 되면 통증을 유발 하고 혈액의 흐름을 방해하기 때문에 손잡이의 접촉면적을 크게 하여 압력이 손바닥 전체에 분배되도록 해야 한다는 Tichauer(1967)의 주장이 있었다. 그러나 이러한 질병 발 생 위험에도 불구하고 특정 수공구들에 대한 압력 평가연구 는 다소 미흡한 실정이다.

본 연구는 포도 순치기 작업으로 인한 손가락과 손목의 피 로도를 경감시키고 궁극적으로는 단순한 상지에 반복작업으 로 발생할 수 있는 누적외상성장해 등의 근골격계질환을 예 방하고자, 최근 농가에서 작업부담이 증가하고 있는 포도재 배 순치기의 전동식 가위(시작품)를 개발하였다. 개발된 순 치기 가위는 자동화된 전동식으로 개발되어 지속적인 순치 기 반복작업이 손쉽게 가능하나, 여러 가지 문제점이 노출되 었다. JSI 평가에서는 수동식 가위보다는 그 위험점수가 줄 어들었으나, 여전히 높은 점수를 나타내었고, 무게가 무겁게 제작된 가위본체와 작업중의 굽은 손목자세는 지속적인 순 치기 작업에 부담이 되는 것으로 평가되었다. 특히 압력분포 평가에서는 수동식 가위보다 현저히 높은 압력분포를 나타 내었는데, 이는 손바닥 그립에 적절하지 못한 손잡이 모양과 무거운 가위 본체와 관련이 있는 것으로 사료되었다.

따라서 본 연구는 선행적으로 개발한 시작품의 단점을 개 선하여 완성한 전동식 가위와 기존에 농가에서 사용되어 온 수동식 가위를 인간공학적인 평가로 다각적으로 비교를 하
고자 한다. 객관적인 평가로는 손의 관절각도 변화와 손 압 력분포, JSI(Job Strain Index)를 이용한 손과 손목의 작업 부하를 평가하였고, 주관적인 평가로는 손 부위에 대한 작업 의 불편도를 설문조사하였다.
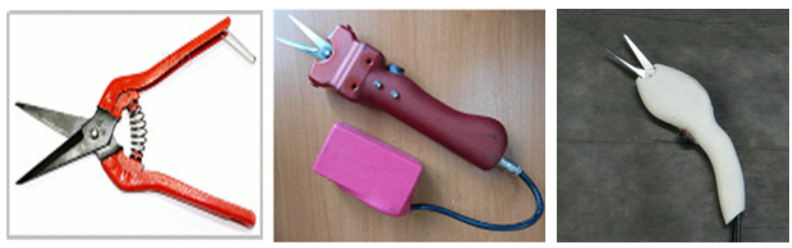

Figure 1. Hand-operated scissors, 1st prototype of Eletro-motion scissors and Completed Eletro-motion scissors

\section{Method}

\subsection{Subject}

피실험자는 21 26세의 남여 대학생 7명을 대상으로 근 육, 신경계통질환 및 부상을 경험한 적이 없는 사람으로 선 정하였다. 사전에 실험내용 및 실험기기, 측정방법에 대해 설명하여 실험에 대한 이해도를 높이고 실험하기 전에 충분 한 휴식을 취하여 심리적 부담을 해소시킨 후에 실험을 수행 하였다.

\subsection{Eletro-motion scissors}

본 연구에서 개발 완성한 전동식 가위는 가동날이 자기력 을 동력으로 동작하며, 본체에 고정된 고정날과 상기 고정날 상에 형성된 회전축을 중심으로 일정 구간을 반복하여 움직 일 수 있는 가동날로 구성되어 작업을 수행하게 된다. 또한 모터의 회전력을 가동날에 전달하기 위한 관련 부품을 생략 하여 구조를 단순화하였고 에너지 변환에 필요한 솔레노이 드를 본체 밖으로 위치시켜 본체를 경량화 하였다.

손잡이의 각도는 손목에 부담이 적은 각도로써, $\mathrm{NIOSH}$ (2004)의 수공구 사용 지침에 따라, 본체 손잡이를 곡선의 굽은 디자인으로 설계하였고 손잡이의 지름, 길이, 소재는 Charles (1999)의 '수공구의 인간공학 디자인'의 사이즈와 형태를 참조하여 작업중의 손의 부담을 감소시키고 안락감 을 줄 수 있는 그립으로 설계하였다.

\subsection{Experiment place and equipments}

실험장소는 인공기후실로 실험진행 중의 물리적인 환경은 
동종 작업시의 작업범위로 조정하여 온도는 26도, 습도는 $63 \%$, 소음은 $66 \mathrm{~dB}$ 로 하였다.

순치기 작업에서 사용되는 손 관절의 각도 변화를 측정하기 위해서 Biometrics사의 전자 각도계(Electro-goniometer) 를 사용하였다(Figure 2). Figure 3과 같이 손가락(검지) 과 손목의 움직이는 각도에 따른 값의 변화를 측정하였다.

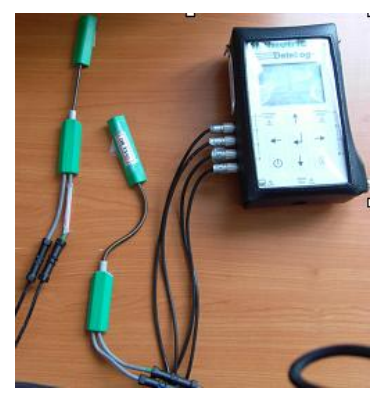

Figure 2. Electro-goniometer

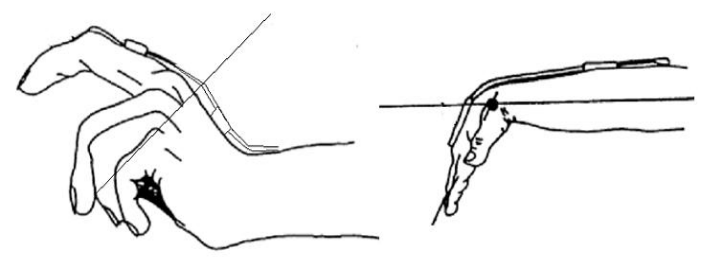

Figure 3. Measuring variation of moving finger and wrist with Electro-goniometer

손 압력분포 측정시스템은 독일 노벨사 Pliance X는 128 sensors인 정압 센서로서 절대치의 압력 값 센서 Hysteresis 가 $3 \%$ 이내이다(Figure 4 ).
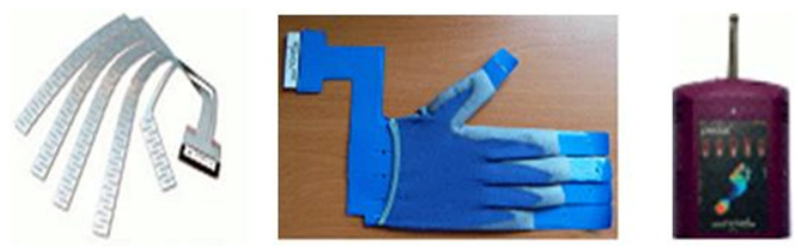

Figure 4. Pressure measurement sensor of hand

\subsection{Experimental design}

개발한 전동식 순치기 가위의 포도 순치기의 작업부담 경 감효과를 평가하기 위해, 독립변수는 전동식 가위의 사용 유 /무로써, 기존 수동식 가위의 작업방식과 전동식 가위를 사 용한 작업방식의 두 수준으로 설계하였다. 종속변수는 손가
락/손목 각도, 손바닥 전체압력(평균, 피크), 손가락별 피크 압력, JSI 점수, 주관적 불편도이다. 통계분석은 SPSS 12.0 을 이용하였고 통계분석 기법은 ANOVA, 통계적 유의수준 은 $\alpha=0.01$ 로 분석하였다.

\subsection{Experiment procedure}

개발한 전동식 순치기 가위의 포도 순치기의 작업능률 향 상을 측정하기 위해, 아래와 같은 절차로 실험을 실시하였다. 1 단계: 모형의 포도 순치기 작업을 할 수 있도록 인공기후 실에 세팅을 한 후, 규정된 작업복을 입는다. 2단계: 손 압력 센서계와 전자 각도계를 착용한다. 3 단계: 포도 순치기 작업을 하기 전에 10 분 휴식을 취한다. 4단계: 선자세에서 전동식 가위 (또는 기존 순치기 가위)를 가지고 순치기 작업을 20 분간 수행한다. 순치기 작 업은 정해진 순만 치게 하여 20 분 동안의 작업량을 측정한다.

5단계: 포도 순치기 작업 후 10 분간 휴식을 취한 후 주관적 불편도를 측정한다.

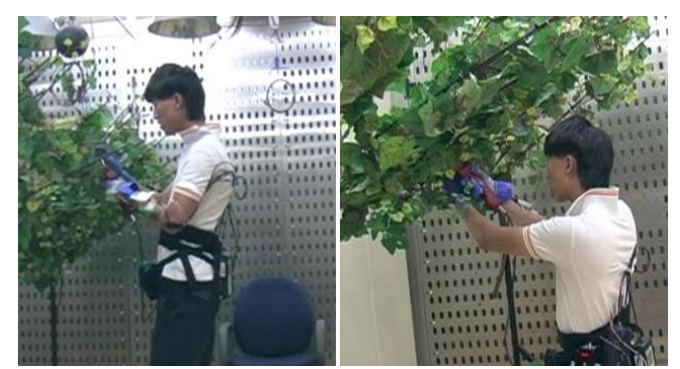

Figure 5. Work postures during the experiment

\section{Results}

본 연구 결과에서는 1 차적으로 개발된 전동식 가위 시작 품의 단점을 보완, 완성한 전동식 가위를 기존 수동식 가위 와 객관적, 주관적 평가를 통하여 비교 분석하였다.

\subsection{Angle variation of finger and wrist}

손 부위별로 2곳(Finger/Wrist flexion-extention)에서 관절 운동범위의 최대, 최소값을 측정하였다. 결과에서 나타 난 바와 같이(Figure 6), 측정된 모든 범위에서 개발된 전동 식 가위가 수동식 가위보다 낮게 나타났다. 특히, 비교적 관 
절각도가 크게 나타났던 손가락 굴곡과 손목 신전에서 각각 51 도, 17 도 낮아졌다. 이에 따라, 전동식 가위가 기존 수동 식 가위보다 손가락, 손목의 관절각도 범위가 개선이 된 것 을 알 수 있다.

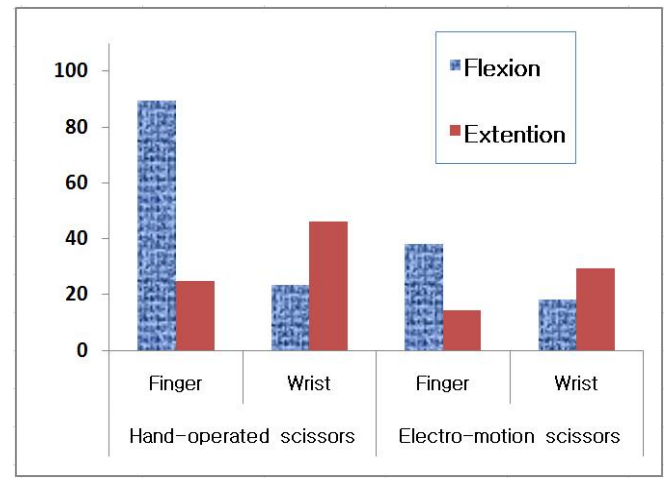

Figure 6. Angle variation of finger and wrist

\subsection{Pressure distribution}

\subsubsection{Whole pressure}

Figure 7과 Figure 8은 전동식 가위의 평균압력과 피 크압력을 기존 수동식 가위와 비교해 나타낸 것이다. 전동 식 순치기 가위는 평균압력이 $19.4 \mathrm{kPa}$ 로 기존 수동식 가위 $(21.2 \mathrm{kPa})$ 보다 다소 낮았고, $25.3 \mathrm{kPa}$ 로 나타났던 시작품

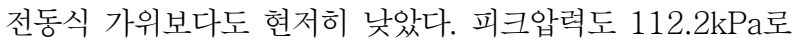
116.2 인 기존 수동식 가위보다 낮게 나타났는데, 이 수치 또한 문제시된 시작품 전동식 가위 $(185.8 \mathrm{kPa})$ 보다 현저히 낮은 수치이다.

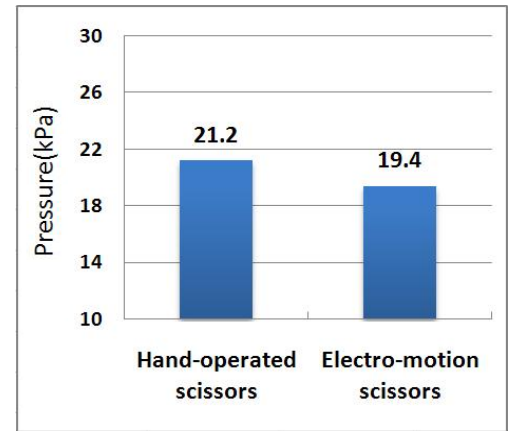

Figure 7. Mean pressure of hand under each conditions

이것은 개선, 완성된 전동식 순치기 가위의 무게가 $240 \mathrm{~g}$ 으로 앞서 개발된(시작품) 전동식 순치기 가위(470g)보다 가벼워졌고 손잡이 부분이 인간공학적인 형태로 디자인된
것이 손의 그립감을 좋게 하여 손 전체의 압력을 낮게 한 것 으로 사료된다.

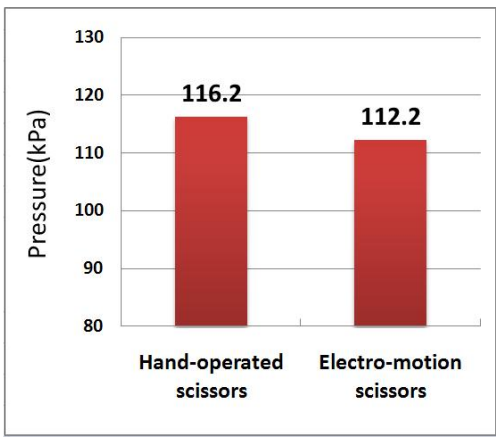

Figure 8. Peak pressure of hand under each conditions

\subsubsection{The pressure according to section}

가위를 사용할 때의 손가락 압력이 고르게 분포되어 있는 지를 알아보기 위하여 손가락의 범위를 구분하여 전동식 가 위를 기존 수동식 가위와 비교, 측정하였다. 이를 위해서는, 각 데이타의 큰 차이를 소멸시켜 주는 평균압력보다는 피크 압력에서 그 의미가 있으므로, 피크압력을 기존 수동식 가위 와 비교, 분석하였다.

Figure 9은 손가락 각 범위별로 2가지 조건(기존 수동식 가위, 개발 완성된 전동식 가위)에서의 각 피크압력을 나타 내고 있다. 전체적으로 전동식 가위의 피크압력은 검지손가 락을 제외하고는 수동식 가위보다 낮게 나타났다. 수동식 가 위의 경우, 각각의 손가락이 큰 차이를 보여 고르지 못한 분 포를 나타내었으며, 이는 통계적으로 유의한 차이를 나타내 었다 $(p<0.01, F=4.22)$. 반면, 전동식 가위는 검지손가락을 제외한 나머지 손가락이 고른 분포를 나타내었다. 이처럼 전

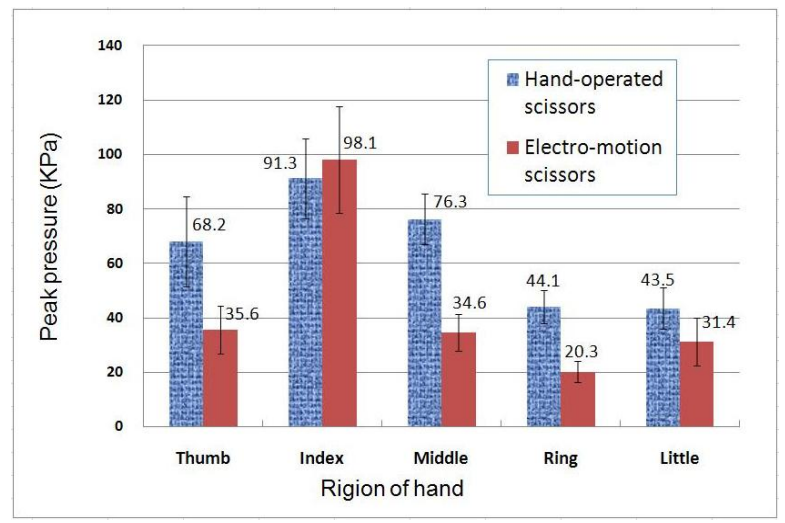

Figure 9. The peak pressure distribution of hand region under each conditions 
Table 1. Job strain index

\begin{tabular}{|c|c|c|c|c|c|c|c|c|c|c|}
\hline & \multirow{2}{*}{\multicolumn{2}{|c|}{ Intensity of exertion }} & \multirow{2}{*}{\multicolumn{2}{|c|}{$\begin{array}{c}\text { Duration of } \\
\text { Exertion }\end{array}$}} & \multirow{2}{*}{\multicolumn{2}{|c|}{$\begin{array}{c}\text { Efforts } \\
\text { per Minute }\end{array}$}} & \multirow{2}{*}{\multicolumn{2}{|c|}{$\begin{array}{c}\text { Hand/Wrist } \\
\text { Posture }\end{array}$}} & \multirow{2}{*}{\multicolumn{2}{|c|}{ Speed of work }} \\
\hline & & & & & & & & & & \\
\hline $\begin{array}{l}\text { Experiment } \\
\text { scissors }\end{array}$ & $\begin{array}{l}\text { Hand- } \\
\text { operated } \\
\text { scissors }\end{array}$ & $\begin{array}{l}\text { Eletro- } \\
\text { motion } \\
\text { scissors }\end{array}$ & $\begin{array}{l}\text { Hand- } \\
\text { operated } \\
\text { scissors }\end{array}$ & $\begin{array}{l}\text { Eletro- } \\
\text { motion } \\
\text { scissors }\end{array}$ & $\begin{array}{l}\text { Hand- } \\
\text { operated } \\
\text { scissors }\end{array}$ & $\begin{array}{l}\text { Eletro- } \\
\text { motion } \\
\text { scissors }\end{array}$ & $\begin{array}{l}\text { Hand- } \\
\text { operated } \\
\text { scissors }\end{array}$ & $\begin{array}{l}\text { Eletro- } \\
\text { motion } \\
\text { scissors }\end{array}$ & $\begin{array}{l}\text { Hand- } \\
\text { operated } \\
\text { scissors }\end{array}$ & $\begin{array}{l}\text { Eletro- } \\
\text { motion } \\
\text { scissors }\end{array}$ \\
\hline $\begin{array}{l}\text { Exposure } \\
\text { cata }\end{array}$ & $\begin{array}{c}\text { Somewhat } \\
\text { Hard }\end{array}$ & Light & $40 \%$ & $35 \%$ & 27 & 24 & $\mathrm{Bad}$ & Good & Average & Average \\
\hline Rating & 2 & 1 & 3 & 3 & 5 & 5 & 4 & 2 & 3 & 3 \\
\hline Multiplier & 3 & 1 & 1.5 & 1.5 & 3 & 3 & 2 & 1 & 1 & 1 \\
\hline \multirow{2}{*}{ JSI score } & \multicolumn{10}{|c|}{$\mathrm{JSI}=\mathrm{IE} \times \mathrm{DE} \times \mathrm{EM} \times \mathrm{HWP} \times \mathrm{SW}$} \\
\hline & \multicolumn{10}{|c|}{ Hand-operated scissors JSI: 27, Eletro-motion scissors JSI: 4.5} \\
\hline
\end{tabular}

동식 가위에서 검지손가락의 피크압력이 나머지 손가락들보 다 현저히 높은 피크압력을 나타낸 것은 버튼을 누를 때 사 용하는 검지손가락의 힘이 압력으로 나타났기 때문인 것으 로 사료된다.

\subsection{The assessment index of work load using JSI}

반 수량적 (semiquantitate)작업 평가방법이라 할 수 있 는 JSI를 사용하여 수동식 가위와 개발 완성된 전동식 가 위를 비교, 평가하였다. 힘을 발휘하는 강도(Intensity of Exertion), 힘을 발휘하는 지속시간(Duration of Exertion), 분당 힘발휘 (Efforts per Minute), 손목의 자세(Hand/Wrist Posture), 작업 속도(Speed of Work) 등 5가지의 작업변 수가 적용되었는데, 기존 수동식 가위의 최종 JSI 점수가 27 로써, JSI 평가의 '위험' 단계인 것으로 나타났다. 반면, 전동식 가위는 4.5로써 '안전' 단계인 것으로 나타났다. 이것 은 전동식 가위의 '힘을 발휘하는 강도', '손목의 자세' 항목에 서 수동식 가위보다 낮은 점수가 나왔기 때문이며, 이 결과 는 전동식 순치기 가위가 상지 말단의 작업인 순치기 작업 과 관련해, 그 위험도를 상당히 낮춘 것이라고 할 수 있다. 한편, 시작품 전동식 가위의 JSI 점수는 6.75 ('작업이 상지 말단의 질환과 관련이 있음' 단계) 였는데, '손/손목의 자세 (HWP)' 변수에서 더 높은 점수(3: Nonneutral)가 나왔기 때문이다. 이를 통해, 개발 완성된 전동식 가위가 시작품 전 동식 가위의 상지동작자세(특히, 손목자세)를 개선했다는 것 또한 알 수 있다.

\subsection{Subjective uncomfortable degree}

주관적인 평가는 각 가위에 대하여, 손 부위에 피험자의 불편도를 10 점 척도법으로 하여, 전혀 불편함이 없는 경우
는 0이라 하고, 매우 불편함이 있는 경우는 10 이라 하여 평 가를 하였다. 수동식 순치기 가위에서는 중지와 검지손가락 에서 불편도가 높은 것으로 나타났고 전동식 가위는 손바 닥을 제외한 모든 부분에서 수동식 순치기 가위보다 낮게 나타났다. 이것은 작업자들이 전동식 가위가 수동식 순치기 가위보다 덜 불편하다고 느끼는 것이라고 말할 수 있고 손바닥 부분이 다소 높게 나타난 것은 전동식 가위가 기존 순치기 가위보다 무게가 무겁기 때문인 것으로 사료된다 (Figure 10).

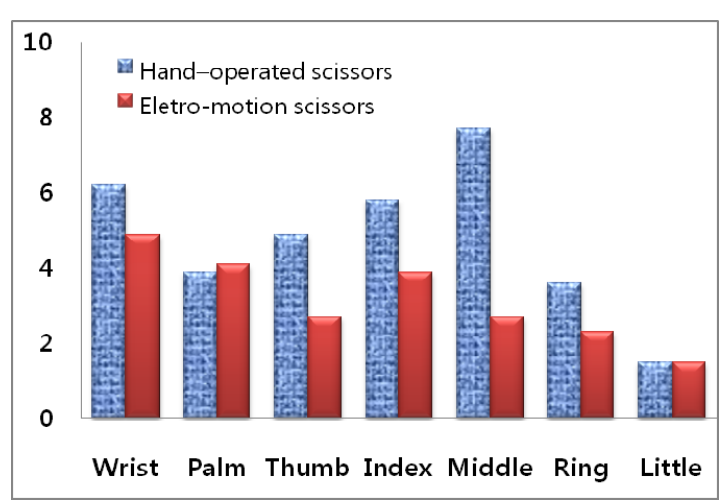

Figure 10. Subjective uncomfortable degree of hand under each conditions.

\section{Conclusion}

본 연구에서는 포도 순치기 작업부하를 감소시키고 근골 격계 질환을 예방하고자 전동식 가위를 개발/개선하여 기존 수동식 가위와 비교, 평가하였다. 
손 압력분포에서는 개발 완성된 전동식 가위가 기존 수동 식 가위보다 평균압력과 피크압력이 다소 낮게 나타났고 범 위별 압력분포에서도 기존 수동식 가위가 손 부위별로 고르 지 못한 압력차를 보이는 반면, 개발 완성된 전동식 가위는 검지손가락을 제외하고는 수동식 순치기 가위보다 고른 압 력분포를 보여, 수공구로 인한 근골격계질환예방에 도움이 될 수 있을 것으로 예상된다. 한편, 앞서 연구된 시작품 전동 식 가위의 압력분포는 작업하는 동안 수동식 가위보다 많은 힘이 필요하지 않음에도 불구하고 전체 평균압력과 피크압 력이 월등히 높게 나타났었는데, 이것은 시작품 전동식 가위 의 무게로 인해 작업하는 동안 이것을 지탱해야 하는 힘이 전체적인 압력으로 나타났기 때문인 것으로 사료되었다. 따 라서 개발 완성된 전동식 가위의 손 전체 평균압력과 피크 압력이 시작품 전동식 가위보다 현저히 낮아진 것으로 보아, 개발 완성된 전동식 가위의 가벼워진 무게와 인간공학적인 손잡이 디자인으로 인해, 그립감이 개선되고 손에 압박이 낮 아진 것을 알 수 있다. Job Strain Index(JSI)기법을 통한 손과 손목의 작업부하 지표를 보면, 개발 완성된 전동식 가 위가 전반적인 손 작업자세가 좋기에 전체적인 작업부하지 표에서 수동식 순치기 가위보다 좋게 나타났다. 주관적 불편 도에서도 전반적으로 개발 완성된 전동식 가위가 수동식 가 위보다 불편도가 적은 것으로 나타나, 객관적인 평가뿐만 아 니라 주관적인 평가에서도 피험자가 전동식 가위 사용을 편 하게 느끼는 것으로 나타났다.

결론적으로, 본 연구에서 개발한 전동식 가위를 이용하여 포도 순치기 작업에 임할 경우, 손의 압력을 분산시키므로, 손의 신경과 혈관을 압박하여 발생하는 통증과 혈액순환방 해로 인한 손의 질병을 예방할 수 있고 컷팅의 자동화로 인 해, 누적외상성 장해(cumulative trauma disorders) 또한 예방하여 포도 순치기 작업부하를 감소시키는 것에 도움이 되는 것으로 나타났다. 나아가, 포도재배 농업인의 상지에 관련된 근골격계질환을 예방할 수 있을 것이며, 수박, 참외 등의 순치기 및 적과 등 각종 반복가위작업과 과수, 조경, 산 림 및 화훼용 작물에 이르는 다양한 작업의 수단으로도 사용 될 수 있을 것으로 예상된다.

반면, 전동식 가위의 객관적 평가에서 나타난 검지손가락 의 높은 압력이 또 다른 질병을 일으킬 소지가 있는 점, 현 장의 고령 작업자들을 대상으로 하지 않고 일반 대학생들이 피험자로 참여했다는 점 등의 연구의 제한점을 갖는다. 검지 손가락의 높은 압력의 경우, 센서 버튼같이 검지손가락의 압 력을 해결할 수 있는 전동식 가위 개발이 대안이 될 수 있을 것이며, 젊은 피험자의 경우, 향후 현장의 고령 작업자들을 대상으로 적용한 연구가 필요할 것으로 사료된다.

\section{Acknowledgements}

This study was carried out with the support of "Research Program for Agricultural Science \& Technology Development (Project No. PJ006517032011)", National Academy of Agricultural Science, Rural Development Administration, Republic of Korea.

\section{References}

Armstrong, T. J. and Chaffin, D. B., Carpal tunnel syndrome and selected personal attributes, Journal of Occupational Medicine, 21(7), 481 $-486,1979$.

Bureau of Labor Statistics (BLS), Workplace Injuries and Illnesses, 2001.

Charles A, Cacha ph.D., "Ergonomics and Safety in Hand Tool Design", Lewis Publishers, 1999.

Hyo-Nam Jeong, et al. Survey of the musculoskeletal disorders of grape farmers, Spring Conference of Ergonomics Society of Korea, 2009.

Kuorinka, I. and Forcier, L., Work-related Musculoskeletal, 1995.

NIOSH(National Institute for Occupational Safety and Health), Stooped and Squatting postures in the Workplace, 2004.

Prosser, R. and Conolly, W. B., Rehabilitation of the Hand \& Upper Limb, Butterworth Heinemann, 2003.

RDA. Disease, Accidnet and Public Health Consciousness of Agriculture, Forestry and fishing worker, 2004.

RDA. Developing Standardization of Diagnosis of Musculoskeletal Disorders for farmer and Assessment of relation with work, 2009.

RDA, The surveillance for the occupational illness and injury of the farm workers, 2010.

Statistics Korea, The surveillance for agriculture and fishery. 2009.

Sung-Hwan Yang, et al. Ergonomics, hyungseul publication, 2004.

Tichauer, E., Ergonomics: The state of the art. American Idustrial Hygiene Association Joural, 28, 105-116, 1967.

Yong-Ku Kong, et al. Grip Force, Finger Force, and Comfort analyses of Young and Old People by Hand Tool Handle Shapes, Journal of the Ergonomics Society of Korea, Vol. 28, No. 2 pp.27-34, 2009.

\section{Author listings}

Hye Seon Chae: hyeseon@korea.kr

Highest degree: MS, Department of Clothing and fashion, Yeungnam University

Position title: Junior Researcher, Department of Agricultural Engineering, National Academy of Agricultural Science, Rural Development Administration

Areas of interest: Development of erg onomic agricultural assistive 
Sung Cheol Kim: paranoid@konkuk.ac.kr

Highest degree: MS, Department of Industrial Engineering, Konkuk University

Position title: Researcher, Department of Agricultural Engineering, National Academy of Agricultural Science, Rural Development

Administration

Areas of interest: Ergonomic product design, Workload evaluation, Ergonomic agricultural equipment

Kwanwoo Kim: kwkim@efact.or.kr

Highest degree: $\mathrm{PhD}$, Department of Industrial Engineering, Tokyo Metropolitan Institute of Technology

Position title: Researcher, Foundation of Agriculture Technical

Commercialization and Transfer

Areas of interest: Ergonomic agricultural machine

Kyung Suk Lee: leeks81@korea.kr

Highest degree: $\mathrm{PhD}$, Department of Clothing and textiles, Seoul National

University

Position title: Senior Researcher, Department of Agricultural Engineering, Academy of Agricultural Science, Rural Development Administration

Areas of interest: Occupational safety and health, Management system
Hyo Cher Kim: alf0416@,korea.kr

Highest degree: MPH, Department of Environmental Health, Seoul National University

Position title: Junior Researcher, Department of Agricultural Engineering, Academy of Agricultural Science, Rural Development Administration Areas of interest: Health and safety, Occupational hazard assessment

Keun Sang Park: ergpark@konkuk.ac,kr

Highest degree: $\mathrm{PhD}$, Department of Industrial Engineering, Nihon University

Position title: Professor, Department of Industrial Engineering, Konkuk University

Areas of interest: Ergonomic product design, Agricultural safety

Date Received : 2011-05-06

Date Revised :2011-10-12

Date Accepted : 2011-10-24 